\title{
Based on DLVO Theory: A Theoretical Model of Boundary Condition for Heavy Oil in Low-Temperature Transportation
}

\author{
Yang LYU ${ }^{1}$, Qiyu Huang ${ }^{2}$, Fuqiang Zhang ${ }^{1}$, Luoqian Liu ${ }^{1}$, Hanwen Zhang ${ }^{1}$, Yan Zhang ${ }^{1}$, \\ Rongbin $\mathrm{Li}^{1}$, Xiangrui Zhu ${ }^{3}$, and Qiuchen Wang ${ }^{1}$ \\ ${ }^{1}$ Affiliation not available \\ ${ }^{2}$ China Univ Petr \\ ${ }^{3}$ China University of Petroleum Beijing
}

November 18, 2020

\begin{abstract}
The low-temperature transportation, a process of gathering and transportation at ultrahigh water content, can incline the energy consumption and elevate the efficiency of the surface gathering system. Here we found that there is the risk of wall sticking of heavy oil in the low-temperature transportation.In this work, a theoretical model of boundary condition for heavy oil in low-temperature transportation based on DLVO theory was proposed to predict the wall sticking occurrence temperature. The outcomes of modeling results had a good agreement in comparison with experiment results (error values: $0.1^{\circ} \mathrm{C} \sim 1.5^{\circ} \mathrm{C}$ ). Moreover, the interaction mechanism of wall sticking was correlated well with the Hamaker constant, radius of oil droplets, Zeta potential, and Debye length.
\end{abstract}

\section{Hosted file}

recovery1-Submit-AICHE Journal.pdf available at https://authorea.com/users/376685/articles/ 493596-based-on-dlvo-theory-a-theoretical-model-of-boundary-condition-for-heavy-oil-inlow-temperature-transportation 